\title{
Effect of Supine Posture on Airway Blood Flow and Pulmonary Function in Stable Heart Failure
}

\author{
Maile L. Ceridon ${ }^{1}$, Norman R. Morris ${ }^{2}$, Thomas P. Olson ${ }^{2}$, Sophie Lalande ${ }^{2}$, Bruce D. \\ Johnson ${ }^{1}$ \\ ${ }^{1}$ Division of Cardiovascular Diseases, Mayo Clinic, Rochester, MN 55905, USA \\ ${ }^{2}$ Griffith University, Griffith Institute of Health, 4222, Australia
}

Running Title: Upright and Supine Position and Bronchial Blood Flow in Heart Failure

Correspondence:

Norman R Morris, PhD

Professor

School of Physiotherapy and Exercise Science

Griffith University

Gold Coast, QLD, 4212

Australia

Phone: 617 -5552-8921

mailto:n.morris@griffith.edu.au

\section{Conflict of Interest}

The authors declare that they have no conflict of interest. 


\section{Abstract:}

Background: The aim of this study was to determine the relationship between body position, pulmonary function (PF) and bronchial blood flow $\left(\mathrm{Q}_{\mathrm{aw}}\right)$ in a group of heart failure (HF) and control subjects. Methods: Thirty-six subjects were studied: 24 stable, ambulatory HF patients (HF: LVEF $=27 \pm 6 \%$, age $=65 \pm 9 y r$ ) and 12 age- and sex-matched controls (CTRL: LVEF $=60 \pm 7 \%$, age $=62 \pm 8 \mathrm{yr}$ ). Measures of $\dot{Q}_{\text {aw }}$ (soluble gas method) and PF were collected upright and following $30 \mathrm{~min}$ in the supine position. $\underline{\text { Results: }} \dot{Q}_{\text {aw }}$ was similar between groups and remained unchanged with body position. Declines in forced vital capacity (FVC) and forced expiratory volume in 1 second $\left(\mathrm{FEV}_{1}\right)$ with the supine position were observed in both groups; declines in forced expiratory flow 25-75\% $\left(\mathrm{FEF}_{25-75}\right)$ and $\mathrm{FEF} 75 \%\left(\mathrm{FEF}_{75}\right)$ with the supine position were observed in the HF group only. Changes in $\dot{Q}_{\text {aw }}$ were related to changes in PF only in the HF patient groups $\left(\triangle \mathrm{FVC}\right.$, \%predicted, $r=-0.45, \mathrm{p}<0.04, \Delta \mathrm{FEV}_{1} \mathrm{r}=-0.61, \mathrm{p}<0.01, \Delta \mathrm{FEV} \mathrm{F}_{1} \%$ predicted, $\mathrm{r}=-$ $0.45, p<0.04)$. Conclusion: These data demonstrate that relationships between postural changes in $\dot{Q}_{\mathrm{aw}}$ and PF exist only in the HF population and that the bronchial circulation may contribute to postural PF decline in HF.

Key Words: Upright and Supine Position, Bronchial Blood Flow, Left Ventricular Systolic Dysfunction 


\section{Introduction:}

In patients with chronic heart failure (HF) the supine posture is associated with a decline in pulmonary function (PF) characterized by an increase in airway resistance, bronchial obstruction and expiratory flow limitation (Duguet et al. 2000; Yap et al. 2000; Boni et al. 2005; Torchio et al. 2006). In acute and severe HF changes in posture may be characterized by an increase in dyspnea known as orthopnea. It has been hypothesized that postural changes in PF and dyspnea in acute HF may be related to changes pulmonary blood volume and altered pulmonary mechanics (expiratory flow limitation) (Duguet et al. 2000). While there been some work examining the postural related changes in PF for acute $\mathrm{HF}$, little work to date has examined the mechanisms by which stable HF pathology combined with the supine position serve to adversely influence PF.

One proposed mechanism for the posture related decline in pulmonary function in stable HF relates to the airway mucosal blood flow $\left(\dot{Q}_{\text {aw }}\right)$. In HF, small changes in airway mucosal blood flow and conductance $\left(\mathrm{G}_{f \text {-aw }}\right)$ have been hypothesized to be related to changes in PF (Mcllveen et al. 1997; Ceridon et al. 2009). Increased $\dot{Q}_{\text {aw }}$ and engorgement of the mucosal vasculature may displace tissue towards the adjacent lumen airspace (Mcllveen 2000; Ceridon et al. 2009) thereby causing an increase in airway obstruction. The airway mucosal vasculature is supplied predominantly from the bronchial circulation, the blood flow to the conducting airways (McCullagh et al. 2010), and we have demonstrated increased airway mucosal blood flow or conductance $\left(\mathrm{G}_{f \text {-aw }}\right)$ are related to increased airway obstruction in HF (Ceridon et al. 2011). Since $\dot{Q}_{\text {aw }}$ arises directly from systemic sources and largely drains into the pulmonary veins, the 
hemodynamics of the circulation are sensitive to changes in both upstream systemic and downstream pulmonary vascular pressures, both of which are affected in chronic HF and by changes in posture (Csete et al. 1990; Mariassy et al. 1991; Baier et al. 1994). Therefore it is possible that an increase of intrathoracic blood volume and pulmonary capillary and venous pressures with the supine position may in turn affect $\dot{Q}_{\mathrm{aw}}$ and $\mathrm{G}_{f \text {-aw }}$ in $\mathrm{HF}$ patients, whereas it may have little or no affect in healthy age-matched individuals.

Therefore, the aim of the present study was to determine the change in $\dot{Q}_{\mathrm{aw}}$, and pulmonary capillary blood volume with body position in stable HF patients relative to healthy age- and sexmatched controls, and to determine how these measures are related to changes in global PF. We hypothesized that an increase in airway obstruction (marked by a decrease of forced expired volume in one second $-\Delta \mathrm{FEV}_{1}$ ) would be associated with an increase in $\dot{Q}_{\mathrm{aw}}$ in $\mathrm{HF}$ on moving to the supine posture, whereas there would be no relationship in healthy, age matched control subjects. 


\section{Methods:}

\section{Ethical Information}

The study complies with the declaration of Helsinki and the protocol was reviewed and approved by the Mayo Clinic Institutional Review Board (IRB 06-002014). All participants provided informed written consent prior to participation.

\subsection{Subjects}

Two groups of subjects were examined: HF patients with symptoms classified as NYHA Class IIV, and age- and sex-matched healthy controls (CTRL). Patients were recruited from the Mayo Clinic Heart Failure Service and from the Cardiovascular Health Clinic. HF inclusion criteria were: primary diagnosis of congestive HF and NYHA categorization, stable (no hospital admissions or medication changes within one month of the study), and a left ventricular ejection fraction $\left(\right.$ LVEF) $<35 \%$. Exclusion criteria included significant obesity (BMI $>35 \mathrm{~kg} / \mathrm{m}^{2}$ ), smoking history $>15$ pack-years, or other co-morbidities that could influence study results separate from the effects of HF (i.e. lung disease, diabetes). All patients maintained their optimized medication regimens while participating in the study. Inclusion criteria for CTRL participants were: normal cardiac function (LVEF $>50 \%$ ), BMI $<35 \mathrm{~kg} / \mathrm{m}^{2}$, a non-significant smoking history (<15 pack-years), and no history of diabetes, lung disease, or coronary artery disease. 


\subsection{Overview of Protocol}

Eligible participants reported to our laboratory on two separate days. Day 1 data collection included measures of PF, hemodynamics and soluble gas measures of cardiac output $(\dot{Q})$, pulmonary capillary blood volume $\left(V_{C}\right)$ and lung membrane diffusing capacity $\left(D_{M}\right)$ in the upright seated position and after 30 minutes of lying in the supine position. Day 2 data collection included direct measures of $\dot{Q}_{\text {aw }}$ while the subject was seated upright and after 30 minutes of lying in the supine position. An estimate of pulmonary capillary wedge pressure (PCWP) was also measured via an abbreviated echocardiogram prior to testing on Day 2.

\subsection{Pulmonary Function Measurements}

Participants underwent spirometry testing in the upright and supine positions. Measures obtained included forced vital capacity (FVC), forced expiratory volume in one second $\left(F E V_{1}\right)$, and mean maximal expiratory flows between 25 and $75 \%$ of $\mathrm{FVC}\left(\mathrm{FEF}_{25-75}\right)$. Measures were collected in accordance with American Thoracic Society (ATS) standards (Miller et al. 2005).

\subsection{Hemodynamics, Pulmonary Capillary Blood Volume and Lung Diffusing Capacity}

Heart rate $(\mathrm{HR})$ and arterial oxygen saturation $\left(\% \mathrm{SaO}_{2}\right)$ were continuously monitored using a pulse oximeter (Nellcor, N595, Dublin, Ireland). Blood pressure (BP) was assessed by sphygmomanometer and was taken by the same technician throughout the entire study.

Rebreathe techniques measuring the simultaneous disappearance of acetylene, carbon monoxide (CO) and nitric oxide (NO) were used to determine $\dot{Q}, \mathrm{D}_{\mathrm{M}}, \mathrm{V}_{\mathrm{C}}$ as described previously 
(Snyder et al. 2006). Briefly, A 5-liter rebreathe bag was filled with $0.3 \%$ carbon monoxide $\left(\mathrm{C}^{18} \mathrm{O}\right), 0.7 \%$ acetylene, $9 \%$ helium, 35\% $\mathrm{O}_{2}, 40$ parts per million (ppm) NO and balance nitrogen. Gases were sampled by mass spectrometer (Perkin-Elmer, MGA 1100, St Louis, USA) and NO analyzer (Sievers Instruments, Boulder, CO, USA); analysis was performed using a custom software package (Snyder et al. 2007). The volume of gas used to fill the rebreathe bag was determined by the tidal volume of the subject. At the end of a normal expiration, endexpiratory lung volume (EELV), the subjects were switched into the rebreathe bag and instructed to nearly empty the bag with each breath for 10 consecutive breaths breathing at a fixed rate.

Following each diffusing capacity maneuver, the rebreathe bag was emptied with a suction device and refilled immediately before the next maneuver. Rebreathe maneuvers were performed in triplicate on each subject.

Calculations of $D_{M}$ and $V_{C}$ were based on the solubility of $C O$ and $N O$ and determined according to the following Roughton-Forster equation (Roughton et al. 1957): $1 / D_{\mathrm{LCO}}=1 / \mathrm{D}_{\mathrm{MCO}}+1 /\left(\Theta_{\mathrm{CO}} \times V_{\mathrm{c}}\right)$, where $1 / \theta=\left(0.73+0058 * P_{A} O_{2}\right) \times(14.6 / \mathrm{Hgb})$, and $D_{M C O}$ is determined from the ratio $D_{\mathrm{LNO}} / \mathrm{D}_{\mathrm{MCO}}=\mathrm{D}_{\mathrm{MNO}} / \mathrm{D}_{\mathrm{MCO}}=\alpha_{\mathrm{NO}} / \alpha_{\mathrm{CO}} \times \mathrm{V}\left(\mathrm{MWCO} / \mathrm{MW}_{\mathrm{NO}}\right)$ which yields a value of 1.99 (Meyer et al. 1990). Additionally, because each maneuver is performed with less than 30 seconds of rebreathing, the recirculation of acetylene, $\mathrm{CO}$, and NO are considered to be negligible (Morris et al. 2007). For our laboratory, the coefficients of variation are $7.2 \%$ for $D_{M}$ and $6.4 \%$ for $V_{C}$. 


\subsection{Measurement of Airway Blood Flow}

$\dot{Q}_{\text {aw }}$ was measured non-invasively using a modified soluble gas technique originally described by Wanner et al (Wanner et al. 2006) as per our previously described methodology (Morris et al. 2008). Briefly, subjects breathed on a mouthpiece connected to a pneumotachometer and a sliding valve system. Gas concentrations for nitrogen $\left(\mathrm{N}_{2}\right)$ and dimethyl ether (DME) were continuously sampled using a mass spectrometer (Perkin-Elmer, MGA 1100, St Louis, USA). Flow, volume, and gas concentration signals were recorded throughout the breathing maneuvers and analysed using custom analysis software (Morris et al. 2008). Subjects were coached through the following breath-hold maneuver. In rapid succession, subjects inhaled to total lung capacity (TLC), slowly expired $\sim 500 \mathrm{ml}$ of air, and inhaled the test gas mix consisting of $9 \% \mathrm{DME}, 91 \% \mathrm{~N}_{2}$ (Praxair, Danbury, CT) back to TLC. Subjects were then coached to hold their breath with an open glottis for a specified time period. A final exhalation was then performed through a critical flow orifice that controlled expiratory flow rate at $\sim 0.25$ liters per second. Breath-hold times were set at 5, 8, 10, and 13 seconds and subjects performed a minimum of two maneuvers at each breath-hold time. In our laboratory, the test-retest reliability for determining resting $Q_{a w}$ is 0.98 with a coefficient of variance of $3.8 \%$ (Morris et al. 2008).

\subsection{Echocardiographic Measures to Estimate of Pulmonary Capillary Wedge Pressure}

Echocardiographic images were acquired using a $4 \mathrm{MHz}$ matrix array cardiac transducer (Vivid 7, General Electric, Milwaukee, WI, USA). All images were acquired with the subject was in a semi-recumbent position from either the apical or parasternal position. Doppler 
echocardiography and tissue Doppler imaging techniques as described by Oh et al. were used to determine early diastolic mitral inflow velocity $(E)$ and medial mitral annulus velocity ( $\left.e^{\prime}\right)$.(Oh et al. 2006) The ratio of the inflow velocity to the annulus velocity (E/e') was then used to noninvasively estimate pulmonary capillary wedge pressure (PCWP) as described by Nagueh et al (Nagueh et al. 1997; Oh et al. 2006).

\subsection{Estimation of Bronchovascular Driving Pressure and Airway Blood Flow Conductance}

Because the bronchial circulation originates from a systemic source and largely drains into left atria via the pulmonary vasculature, flow in the bronchial vascular bed is affected by both upstream systemic pressures and by downstream pulmonary pressures (Wagner et al. 1990). An estimate of the perfusion pressure across the airway circulatory bed $\left(\Delta \mathrm{P}_{\mathrm{aw}}\right)$ was calculated as the difference between systemic mean arterial pressure (MAP) and the estimated PCWP or as (MAP-PCWP). Airway blood flow conductance through the airway circulation $\left(\mathrm{G}_{f \text {-aw }}\right)$ was calculated as $\dot{Q}_{\text {aw }}$ divided by $\Delta \mathrm{P}_{\text {aw }}$. Note that for this study we could only report a single semirecumbent PCWP due to technical limitations in reporting upright and supine echocardiographic measures. Hence we report only a single $\mathrm{G}_{f \text {-aw }}$ for the study rather than specific upright and supine values.

\subsection{Data Analysis}

All statistical comparisons were made using the SPSS statistical software package (Version 12.0, Chicago, IL). Two way ANOVA with repeated measures was used to compare variables between groups (CTRL and HF) and body position (upright versus supine). Correlation analysis was 
performed (Pearson product moment correlation coefficient $-r$ ) to examine any relationship between postural changes in PF and $\dot{Q}_{\text {aw }}$. Significance was set at $\alpha=0.05$. Values are reported as mean $\pm S D$ unless otherwise noted. 


\section{Results:}

Subject characteristics and medications are summarized in Table 1. Thirty-six subjects completed testing, twenty-four HF patients (HF), and twelve age- and sex-matched healthy controls (CTRL). Within the HF group, 13 were NYHA Class I-II and 11 were NYHA Class III-IV. All HF subjects had stable systolic HF and were well managed. While both groups were of similar age and gender mix, HF patients had significantly greater body mass index and significantly lower EF, when compared to CTRL.

\subsection{Hemodynamics, Pulmonary Capillary Blood Volume and Lung Diffusing Capacity}

Hemodynamic and diffusing capacity measures are summarized in Table 2. Compared to CTRL, PCWP for the HF group was higher (CTRL: $11.3 \pm 2.1 \mathrm{mmHg}, \mathrm{HF}: 21.3 \pm 8.0 \mathrm{mmHg}, \mathrm{p}<0.001$ ). Systemic blood pressure measurements were higher for CTRL compared to HF and as a result, calculated $\Delta \mathrm{P}_{\text {aw }}$ was lower for HF (CTRL: $\left.80.1 \pm 12.6 \mathrm{mmHg}, \mathrm{HF}: 58.9 \pm 15.6 \mathrm{mmHg}, \mathrm{p}<0.001\right)$. With the supine posture, values for SV were higher in both groups ( $p<0.05$ relative to upright). In the CTRL group, SV increased $(p<0.05)$ and HR decreased $(p<0.05)$ resulting in no overall change in $\dot{Q}$. For the HF group, SV increased $(p<0.05)$ and HR remained unchanged in the supine position, resulting in a significant increase in $\dot{Q}(\mathrm{p}<0.05)$. Neither group exhibited a significant change in systemic blood pressures with body position.

Pulmonary capillary blood volumes were significantly lower in the HF group when compared to CTRL in both upright and supine positions (Table 2, $p<0.05$ ). Measures of $D L_{c o}$ and $D_{M}$ were not 
significantly different between groups and there was no significant change in $D_{C O}, D_{M}$ or $V_{C}$ for either group when moving from upright to supine.

\subsection{Pulmonary Function Measurements}

PF measures in upright and supine are reported in Table 3. In the upright position, HF subjects had a significantly lower $\mathrm{FEV}_{1}(\mathrm{p}<0.05)$. In moving to the supine posture, both groups demonstrated declines in FVC and $\mathrm{FEV}_{1}(\mathrm{p}<0.05)$ (Table 3$)$. For the HF group, the change in posture also resulted in a significant decrease in $\mathrm{FEF}_{25-75}$ and $\mathrm{FEF}_{75}($ Table 3, $\mathrm{p}<0.05$ ).

\subsection{Measures of $\dot{Q}_{\mathrm{aw}}, G_{f-a w}$}

Measures of $\dot{Q}_{\text {aw }}$ were similar between groups in both the upright and in the supine position (Figure 1). Compared to CTRL, $\mathrm{G}_{f \text {-aw }}$ values were significantly elevated in $\mathrm{HF}$ in both the upright and supine positions however no significant differences in $\mathrm{G}_{\text {-aw }}$ were observed between the upright and supine positions for either group (Figure 1).

\subsection{Relationships of $\dot{Q}_{\mathrm{aw}}$ to Pulmonary Function}

For CTRL there was no significant relationship between the change in PF and the change in $\dot{Q}_{\text {aw }}$ $\left(\Delta \dot{Q}_{\text {aw }}\right)$ when moving from upright to supine. For $\mathrm{HF}, \Delta \dot{Q}_{\text {aw }}$ when moving from upright to supine

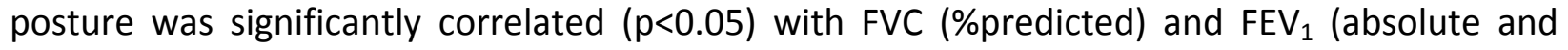
\%predicted) and tended to be negatively correlated with changes in FVC (absolute, $\mathrm{P}=0.08$ )

(Figure 2). Changes in $\dot{Q}_{\text {aw }}$ were not significantly related to the change in $\mathrm{DL}_{\mathrm{CO}}, \mathrm{D}_{\mathrm{M}}$ or $\mathrm{V}_{\mathrm{C}}$ when moving from the upright to supine posture. 


\section{Discussion:}

Using a modified soluble gas technique to measure $\dot{\mathrm{Q}}_{\mathrm{aw}}$, our data demonstrate that in stable $\mathrm{HF}$ patients, postural induced increases in $\dot{\mathrm{Q}}_{\mathrm{aw}}$ appear to be related to decreases in PF, particularly $\Delta \mathrm{FEV}_{1}$. Our data demonstrate that in stable $\mathrm{HF}$ patients, postural induced increases in $\dot{Q}_{\mathrm{aw}}$ appear to be related to decreases in PF, particularly $\triangle \mathrm{FEV}_{1}$. These results suggest a possible contribution of bronchovascular hemodynamics to postural PF abnormalities in a stable HF patient population.

The decline in PF when moving from an upright to a supine posture in both healthy and HF patients is well documented (Chang et al. 1992; Duguet et al. 2000; Yap et al. 2000; Martin-Du Pan et al. 2004; Boni et al. 2005). In healthy individuals (Linderholm et al. 1962) established that the upright to supine decreases in PF were largely due to reductions in lung volumes. The cephalic shift of the diaphragm combined with an increase in blood volume within the thoracic cavity displaces enough airspace volume within the lungs to cause the observed drop in PF (Linderholm et al. 1962).

For HF patients, these postural changes may also impact on the bronchial vasculature and alter airway caliber. (Mcllveen 2000) has suggested that even in mild HF excessive myocardial stretch may result in blocking of afferent mediated bronchial vasoconstriction and produce a mucosal swelling and bronchial congestion. With the supine position, a translocation of blood volume back to the thoracic cavity is known to occur and in cases of left ventricular 
insufficiency, this shift can noticeably increase capillary and venous vascular pressures in the pulmonary circulation (Linderholm et al. 1962). It has been suggested that in HF patients, this shift in fluid volume contributes to vascular distension and/or interstitial edema, subsequently leading to thoracic space limitations, compression of the airways, and ultimately to the observed increase in expiratory flow limitations commonly observed while lying down versus while seated in this patient population (Linderholm et al. 1962; Yap et al. 2000; Martin-Du Pan et al. 2004; Torchio et al. 2006; Pecchiari et al. 2009). We believe that our results are consistent with these findings in that while we saw a decline in PF in both HF and CTRL groups, the decline in PF was only correlated with the increase in $\Delta \dot{Q}_{\text {aw }}$ for the HF group (Figure 2).

An extrapolation of these observations would support the hypothesis that the rise in central blood volume and left heart pressures may serve to dilate the bronchovasculature. The implications of this proposed mechanism are that the already elevated bronchovascular conductance of HF patients would be subject to further increases with the supine position, thereby altering the mechanical properties of the airways and contributing to the decline in PF. Surprisingly there was no change in $V_{C}$ after 30 minutes of being supine and no significant relationship between changes in $V_{c}$ and $\dot{Q}_{\text {aw }}$. However changes in central blood volume may well occur independent of $V_{c}$ in healthy and heart disease patients (Gazioglu et al. 1967) and this may explain the lack of a significant relationship between changes in $\mathrm{V}_{\mathrm{c}}$ and $\dot{Q}_{\text {aw }}$ observed in the current study. 
We found the decline in pulmonary function when moving from upright to supine, was similar for both HF and control subjects (Table 3). Several other studies have reported that the postural decline in $\mathrm{PF}$ is greater particularly in patients with acute $\mathrm{HF}$, when compared to control subjects (Duguet et al. 2000; Yap et al. 2000; Boni et al. 2005; Torchio et al. 2006). This difference in our results, when compared to others, may be due to the fact that patients examined in the present study were stable with a relatively controlled HF disease status. It is worth noting that no HF subjects complained of shortness of breath while lying supine.

Therefore, in $\mathrm{HF}$ it is possible that the mechanical properties of the lungs, and not just lung volumes, are significantly altered with positional changes in HF. The specific mechanisms accounting for the magnitude of these declines in this patient population are complex and have yet to be fully elucidated. What is known is that the time course for the observed PF changes is relatively fast, with the onset of the PF decline occurring within a few minutes of the onset of supine posture, and relatively reversible (only small residual increases remain) within a few minutes of resuming upright posture in subjects that are not acutely decompensated (Yap et al. 2000). Also, measures of inspiratory pressure, work of breathing, and/or diaphragmatic strength are known to be strongly correlated to supine PF declines in moderate-severe HF patients (Killian et al. 1982; Killian et al. 1988; Nava et al. 2003). Nava and colleagues concluded that both elastic (less lung compliance) and resistive loads are simultaneously increased with the supine position in this patient population (Nava et al. 2003). When these loads were lessened with non-invasive mechanical ventilation, dyspneic symptomology was significantly improved. 
Surprisingly we did not find a relationship between the $\Delta \mathrm{FEF}_{25-75 \%}$ and $\Delta \dot{Q}_{\text {aw }}$ when moving from upright to supine. Given that changes in $\mathrm{FEF}_{25-75 \%}$ reflect small airway involvement, we would have expected this to be related to changes $\dot{Q}_{\text {aw }}$ during the postural challenge. It is possible that this failure to detect a change in $\mathrm{FEF}_{25-75 \%}$ reflects a limitation in the technique used to determine $\dot{Q}_{\text {aw }}$. The soluble gas method used in the current study represents gross measurement of blood flow from all airway mucosa (both large and small) and may be unable to differentiate between the blood flow from smaller and larger airway airways. As such the technique may lack the sensitivity to detect the subtle relationship between $\dot{Q}_{\text {aw }}$ and $\mathrm{FEF}_{25-75 \% \text {. }}$

Our results need to be viewed within the limitations of the experimental design. We chose not to study acute or more severe HF patients in the current study so as to determine the impact of postural changes in mild-moderate, well compensated HF. However, we note that the fact that we found a relationship between postural changes and $\dot{Q}_{\text {aw }}$ in this population is indeed significant and future studies should focus on examining PF and $\dot{Q}_{\text {aw }}$ changes in more severe patients suffering from orthopnea.

In conclusion, we demonstrated that the acute intervention of supine posture does not significantly change mean $\dot{Q}_{\text {aw }}$ in HF patients or in CTRL subjects. Postural induced changes in bronchovascular flow were related to changes in pulmonary function in HF patients and suggest that changes in the bronchial circulation with supine posture may contribute to postural 
pulmonary function declines and/or the orthopnea symptoms common in more severe, acute HF patients.

\section{Acknowledgements}

The authors would like to thank the subjects for their participation in our study and contributions of Jennifer Fitz-Gibbon and Dr. Lyle J. Olson in the recruitment and daily testing. We would also like to thank Dr. Kenneth C. Beck for his his technical expertise and Dr Adam Wanner for his input and guidance in setting up the airway blood flow technique in our laboratory. This study was supported by the National Institute of Health Grant [HL71478]. 


\section{References:}

Baier, H., D. Onorato, J. Barker and A. Wanner (1994). "Tracheal mucosal edema in hydrostatic pulmonary edema." J Appl Physiol 77(1): 352-356.

Boni, E., M. Bezzi, L. Carminati, L. Corda, V. Grassi and C. Tantucci (2005). "Expiratory flow limitation is associated with orthopnea and reversed by vasodilators and diuretics in left heart failure." Chest 128(2): 1050-1057.

Ceridon, M., N. R. Morris, M. L. Hulsebus, T. P. Olson, S. Lalande and B. D. Johnson (2011). "Influence of bronchial blood flow and conductance on pulmonary function in stable systolic heart failure." Respiratory Physiology \& Neurobiology. doi:10.1016/j.resp.2011.04.020

Ceridon, M., A. Wanner and B. D. Johnson (2009). "Does the bronchial circulation contribute to congestion in heart failure?" Med Hypotheses.

Chang, S. C., H. I. Chang, S. Y. Liu, G. M. Shiao and R. P. Perng (1992). "Effects of body position and age on membrane diffusing capacity and pulmonary capillary blood volume." Chest 102(1): 139-142.

Csete, M. E., W. M. Abraham and A. Wanner (1990). "Vasomotion influences airflow in peripheral airways." Am Rev Respir Dis 141(6): 1409-1413.

Duguet, A., C. Tantucci, O. Lozinguez, R. Isnard, D. Thomas, M. Zelter, J. P. Derenne, J. MilicEmili and T. Similowski (2000). "Expiratory flow limitation as a determinant of orthopnea in acute left heart failure." J Am Coll Cardiol 35(3): 690-700.

Gazioglu, K. and P. N. Yu (1967). "Pulmonary blood volume and pulmonary capillary blood volume in valvular heart disease." Circulation 35(4): 701-709.

Killian, K. J., D. D. Bucens and E. J. Campbell (1982). "Effect of breathing patterns on the perceived magnitude of added loads to breathing." J Appl Physiol 52(3): 578-584.

Killian, K. J. and N. L. Jones (1988). "Respiratory muscles and dyspnea." Clin Chest Med 9(2): 237-248.

Linderholm, H., P. Kimbel, D. H. Lewis and A. B. Dubois (1962). "Pulmonary capillary blood flow during cardiac catheterization." J Appl Physiol 17: 135-141.

Mariassy, A. T., H. Gazeroglu and A. Wanner (1991). "Morphometry of the subepithelial circulation in sheep airways. Effect of vascular congestion." Am Rev Respir Dis 143(1): 162-166.

Martin-Du Pan, R. C., R. Benoit and L. Girardier (2004). "The role of body position and gravity in the symptoms and treatment of various medical diseases." Swiss Med Wkly 134(37-38): 543-551.

McCullagh, A., M. Rosenthal, A. Wanner, A. Hurtado, S. Padley and A. Bush (2010). "The bronchial circulation--worth a closer look: a review of the relationship between the bronchial vasculature and airway inflammation." Pediatric Pulmonology 45(1): 1-13.

Mcllveen, S., S. White and G. Parsons (1997). "Autonomic control of bronchial circulation in awake sheep during rest and behaviour." Clin Exp Pharmacol Physiol 24(12): 940-947.

Mcllveen, S. A. (2000). "Bronchovascular role in pulmonary congestion." Clin Exp Pharmacol Physiol 27(12): 1045-1048.

Meyer, M., K. D. Schuster, H. Schulz, M. Mohr and J. Piiper (1990). "Pulmonary diffusing capacities for nitric oxide and carbon monoxide determined by rebreathing in dogs." J Appl Physiol 68(6): 2344-2357.

Miller, M. R., J. Hankinson, V. Brusasco, F. Burgos, R. Casaburi, A. Coates, R. Crapo, P. Enright, C. P. van der Grinten, P. Gustafsson, R. Jensen, D. C. Johnson, N. Maclntyre, R. McKay, D. Navajas, O. F. Pedersen, R. Pellegrino, G. Viegi and J. Wanger (2005). "Standardisation of spirometry." Eur Respir J 26(2): 319-338. 
Morris, N. R., M. L. Ceridon, K. C. Beck, N. A. Strom, D. A. Schneider, E. S. Mendes, A. Wanner and B. D. Johnson (2008). "Exercise-related change in airway blood flow in humans: relationship to changes in cardiac output and ventilation." Respir Physiol Neurobiol 162(3): 204-209.

Morris, N. R., E. M. Snyder, K. C. Beck, L. J. Haseler, L. J. Olson and B. D. Johnson (2007). "The relationship between resting lung-to-lung circulation time and peak exercise capacity in chronic heart failure patients." J Card Fail 13(5): 389-394.

Nagueh, S. F., K. J. Middleton, H. A. Kopelen, W. A. Zoghbi and M. A. Quinones (1997). "Doppler tissue imaging: a noninvasive technique for evaluation of left ventricular relaxation and estimation of filling pressures." J Am Coll Cardiol 30(6): 1527-1533.

Nava, S., M. T. Larovere, F. Fanfulla, P. Navalesi, M. Delmastro and A. Mortara (2003). "Orthopnea and inspiratory effort in chronic heart failure patients." Respir Med 97(6): 647-653.

Oh, J. K., J. B. Seward and A. J. Tajik (2006). The echo manual. Philadelphia, Lippincott Williams \& Wilkins.

Pecchiari, M., T. Anagnostakos, E. D'Angelo, C. Roussos, S. Nanas and A. Koutsoukou (2009). "Effect of heliox breathing on flow limitation in chronic heart failure patients." Eur Respir J 33(6): 1367-1373.

Roughton, F. J. and R. E. Forster (1957). "Relative importance of diffusion and chemical reaction rates in determining rate of exchange of gases in the human lung, with special reference to true diffusing capacity of pulmonary membrane and volume of blood in the lung capillaries." J Appl Physiol. 11(2): 290-302.

Snyder, E. M., K. C. Beck, M. L. Hulsebus, J. F. Breen, E. A. Hoffman and B. D. Johnson (2006). "Short-term hypoxic exposure at rest and during exercise reduces lung water in healthy humans." J Appl Physiol 101(6): 1623-1632.

Snyder, E. M., K. C. Beck, S. T. Turner, E. A. Hoffman, M. J. Joyner and B. D. Johnson (2007). "Genetic variation of the beta2-adrenergic receptor is associated with differences in lung fluid accumulation in humans." J Appl Physiol 102(6): 2172-2178.

Torchio, R., C. Gulotta, P. Greco-Lucchina, A. Perboni, L. Avonto, H. Ghezzo and J. Milic-Emili (2006). "Orthopnea and tidal expiratory flow limitation in chronic heart failure." Chest 130(2): 472-479.

Wagner, E. M. and W. A. Mitzner (1990). "Effect of left atrial pressure on bronchial vascular hemodynamics." J Appl Physiol 69(3): 837-842.

Wanner, A., E. S. Mendes and N. D. Atkins (2006). "A simplified noninvasive method to measure airway blood flow in humans." J Appl Physiol 100(5): 1674-1678.

Yap, J. C., D. M. Moore, J. G. Cleland and N. B. Pride (2000). "Effect of supine posture on respiratory mechanics in chronic left ventricular failure." Am J Respir Crit Care Med 162(4 Pt 1): 1285-1291. 
Table 1: Subject Characteristics

\begin{tabular}{|c|c|c|}
\hline Characteristic & CTRL & HF \\
\hline $\mathrm{N}$ (female) & $12(3)$ & $24(5)$ \\
\hline Age (years) & $63 \pm 9$ & $65 \pm 8$ \\
\hline Body Mass Index $\left(\mathrm{kg} / \mathrm{m}^{2}\right)$ & $25.5 \pm 3.5$ & $29.5 \pm 4.5^{*}$ \\
\hline Body Surface Area $\left(\mathrm{m}^{2}\right)$ & $2.0 \pm 0.2$ & $2.0 \pm 0.2$ \\
\hline Ejection Fraction (\%) & $60.7 \pm 6.3$ & $26.9 \pm 6.0 * *$ \\
\hline PCWP (mmHg) & $11.3 \pm 2.1$ & $21.3 \pm 1.4 * *$ \\
\hline \multicolumn{3}{|l|}{ Medications } \\
\hline Aspirin & $25 \%(3)$ & $83 \%(20)$ \\
\hline ACE-Inhibitor & $0 \%(0)$ & $75 \%(18)$ \\
\hline Angiotensin II receptor antagonist & $0 \%(0)$ & $21 \%(5)$ \\
\hline$\beta$-Adrenergic receptor antagonist & $0 \%(0)$ & $96 \%(23)$ \\
\hline$\beta 1$-selective antagonist & - & $29 \%(7)$ \\
\hline Non-selective antagonist & - & $71 \%(17)$ \\
\hline Digitalis & $0 \%(0)$ & $58 \%(14)$ \\
\hline Diuretic & $6 \%(1)$ & $67 \%(16)$ \\
\hline Statin & $25 \%(3)$ & $58 \%(14)$ \\
\hline
\end{tabular}


Table 2: Hemodynamics, and Lung Diffusing Capacity

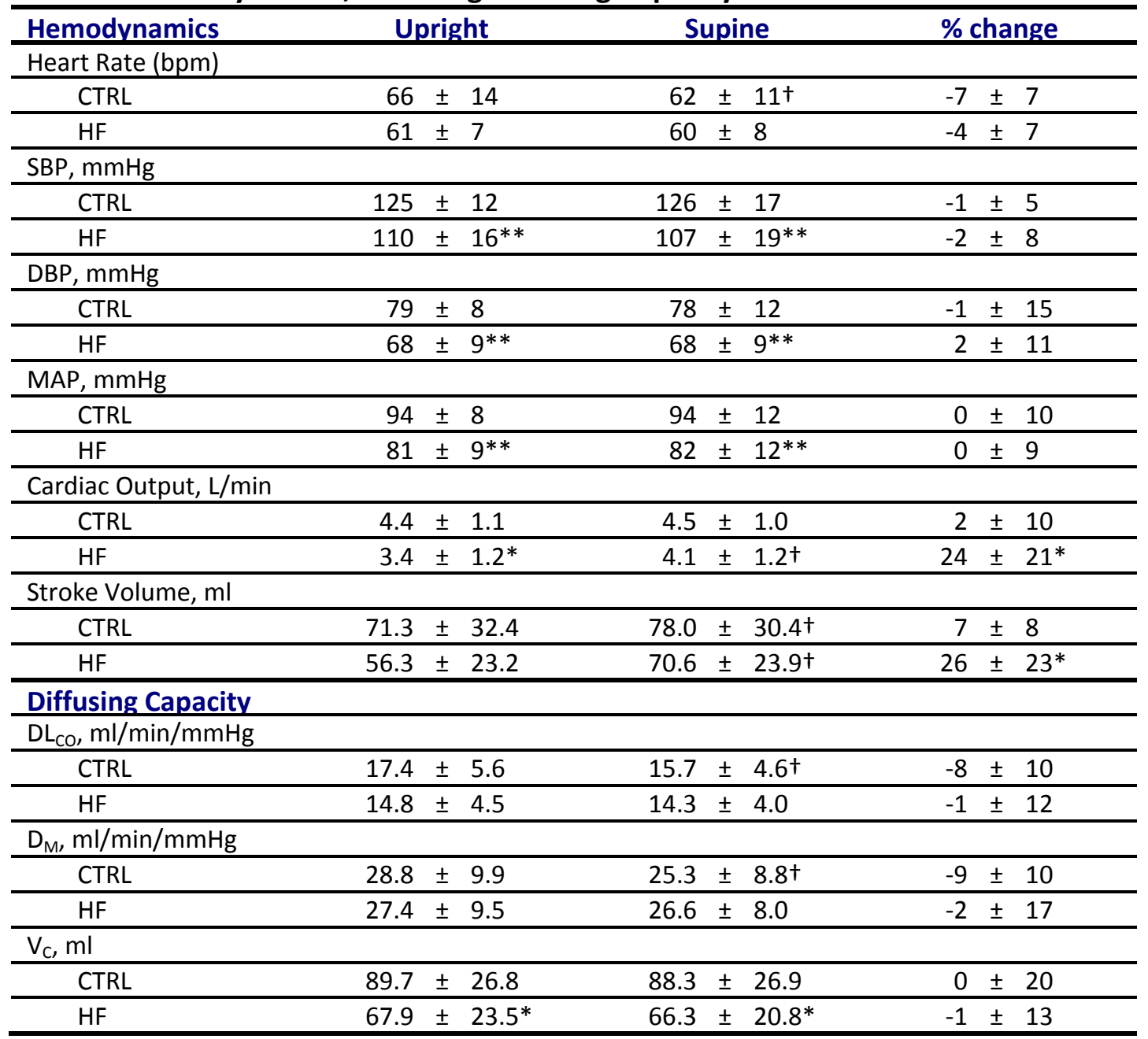

$\mathrm{SBP}=$ systolic blood pressure (systemic), $\mathrm{DBP}=$ diastolic blood pressure (systemic), MAP = mean arterial pressure (systemic), $\mathrm{SV}=$ stroke volume, $\mathrm{DL}_{\mathrm{CO}}=$ diffusing capacity of the lung for $\mathrm{CO}, \mathrm{D}_{\mathrm{M}}=$ diffusing capacity for the entire lung membrane, $V_{C}=$ pulmonary capillary blood volume. Data reported as mean \pm SD.

${ }^{*} p<0.05$ compared to CTRL. ${ }^{* *} p<0.01$ compared to CTRL. ${ }^{*} p<0.05$ when compared to Upright. 
Table 3: Pulmonary Function Testing and Lung Volumes

\begin{tabular}{|c|c|c|c|}
\hline & Upright & Supine & $\%$ change \\
\hline \multicolumn{4}{|c|}{ Pulmonary Function } \\
\hline \multicolumn{4}{|l|}{ FVC, L } \\
\hline CTRL & $4.3 \pm 0.9$ & $4.0 \pm 1.0 \dagger$ & $-9 \pm 7$ \\
\hline$\%$ predicted & $98 \pm 16$ & $89 \pm 16^{+}$ & \\
\hline $\mathrm{HF}$ & $3.7 \pm 1.0$ & $3.3 \pm 1.0 \dagger$ & $-10 \pm 10$ \\
\hline$\%$ predicted & $86 \pm 11^{*}$ & $77 \pm 13^{*+}$ & \\
\hline \multicolumn{4}{|l|}{ FEV $_{1}, \mathrm{~L}$} \\
\hline CTRL & $3.5 \pm 0.8$ & $3.1 \pm 0.8^{\dagger}$ & $-10 \pm 6$ \\
\hline$\%$ predicted & $100 \pm 13$ & $90 \pm 12+$ & \\
\hline $\mathrm{HF}$ & $2.8 \pm 0.9^{*}$ & $2.5 \pm 0.8^{* \dagger}$ & $-13 \pm 10$ \\
\hline$\%$ predicted & $85 \pm 15^{*}$ & $74 \pm 15^{*+}$ & \\
\hline \multicolumn{4}{|l|}{ FEV $_{1} /$ FVC } \\
\hline CTRL & $82 \pm 6$ & $80 \pm 10$ & $0 \pm 6$ \\
\hline $\mathrm{HF}$ & $77 \pm 9$ & $74 \pm 10$ & $-3 \pm 8$ \\
\hline \multicolumn{4}{|l|}{$\mathrm{FEF}_{25-75}, \mathrm{~L} / \mathrm{sec}$} \\
\hline CTRL & $3.5 \pm 1.4$ & $3.1 \pm 1.3$ & $-9 \pm 18$ \\
\hline \%predicted & $114 \pm 42$ & $101 \pm 22$ & \\
\hline $\mathrm{HF}$ & $2.7 \pm 1.2$ & $2.1 \pm 1.1^{* \dagger}$ & $-20 \pm 17$ \\
\hline$\%$ predicted & $91 \pm 39$ & $72 \pm 33^{*+}$ & \\
\hline \multicolumn{4}{|l|}{$\mathrm{FEF}_{75}, \mathrm{~L} / \mathrm{sec}$} \\
\hline CTRL & $1.4 \pm 0.8$ & $1.2 \pm 0.5$ & $4 \pm 40$ \\
\hline \%predicted & $95 \pm 40$ & $91 \pm 37$ & \\
\hline $\mathrm{HF}$ & $1.0 \pm 0.5$ & $0.8 \pm 0.4^{*+}$ & $-22 \pm 24 *$ \\
\hline$\%$ predicted & $69 \pm 30^{*}$ & $67 \pm 44+$ & \\
\hline
\end{tabular}




\section{Figure Legends}

Figure 1: Airway blood flow and airway blood flow conductance in the upright and supine positions. Grey bars represent upright seated position, black bars represent supine position. Data reported as mean \pm SE. ${ }^{*} p<0.05$ when compared to CTRL.

Figure 2: Correlation between the $\Delta \mathrm{Q}_{\mathrm{aw}} \Delta \mathrm{FVC}$ (L), $\Delta \mathrm{FVC}$ (\%predicted), $\Delta \mathrm{FEV}_{\mathbf{1}}$ (L) and $\Delta \mathrm{FEV}_{1}$ (\%predicted) from the upright to the supine position for HF groups only. The center line (solid) represents the linear fit trendline, the outside lines (dotted) represents the 95\% confidence interval to the linear fit line. $F V C=$ forced vital capacity, $F E V_{1}=$ forced expiratory volume in 1 second. 
Figure 1: Airway blood flow and airway blood flow conductance in the upright and supine positions.
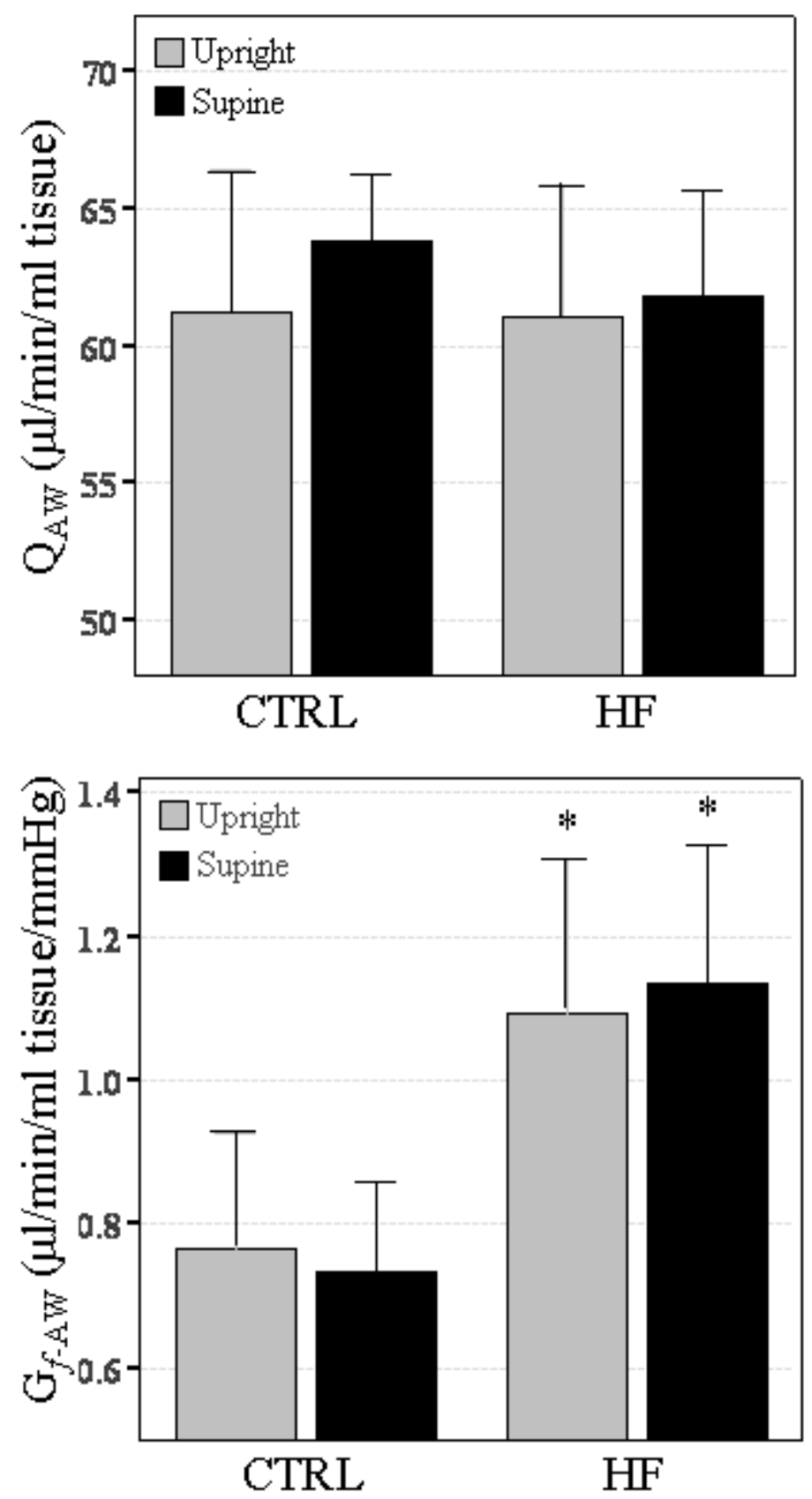

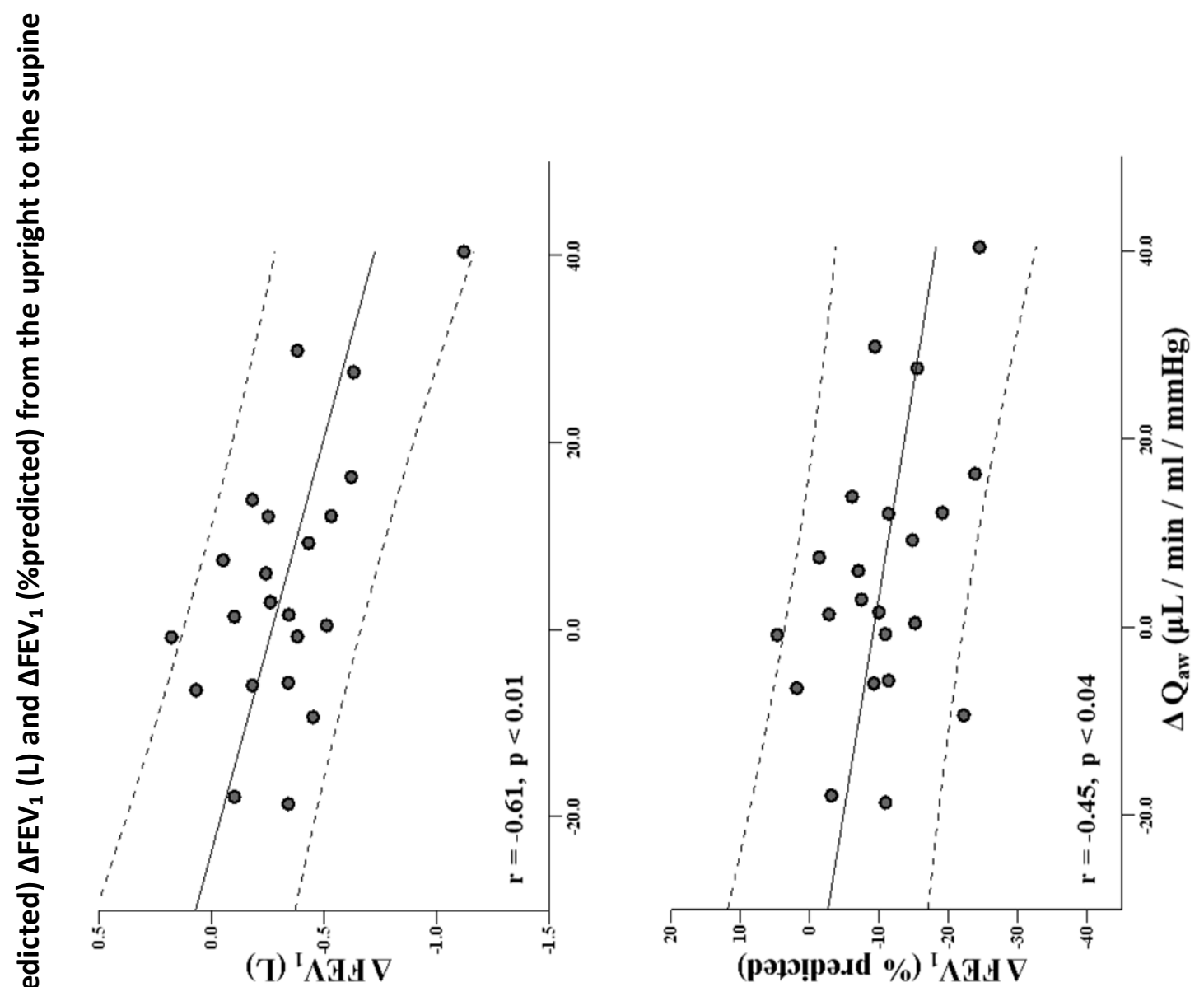

흥
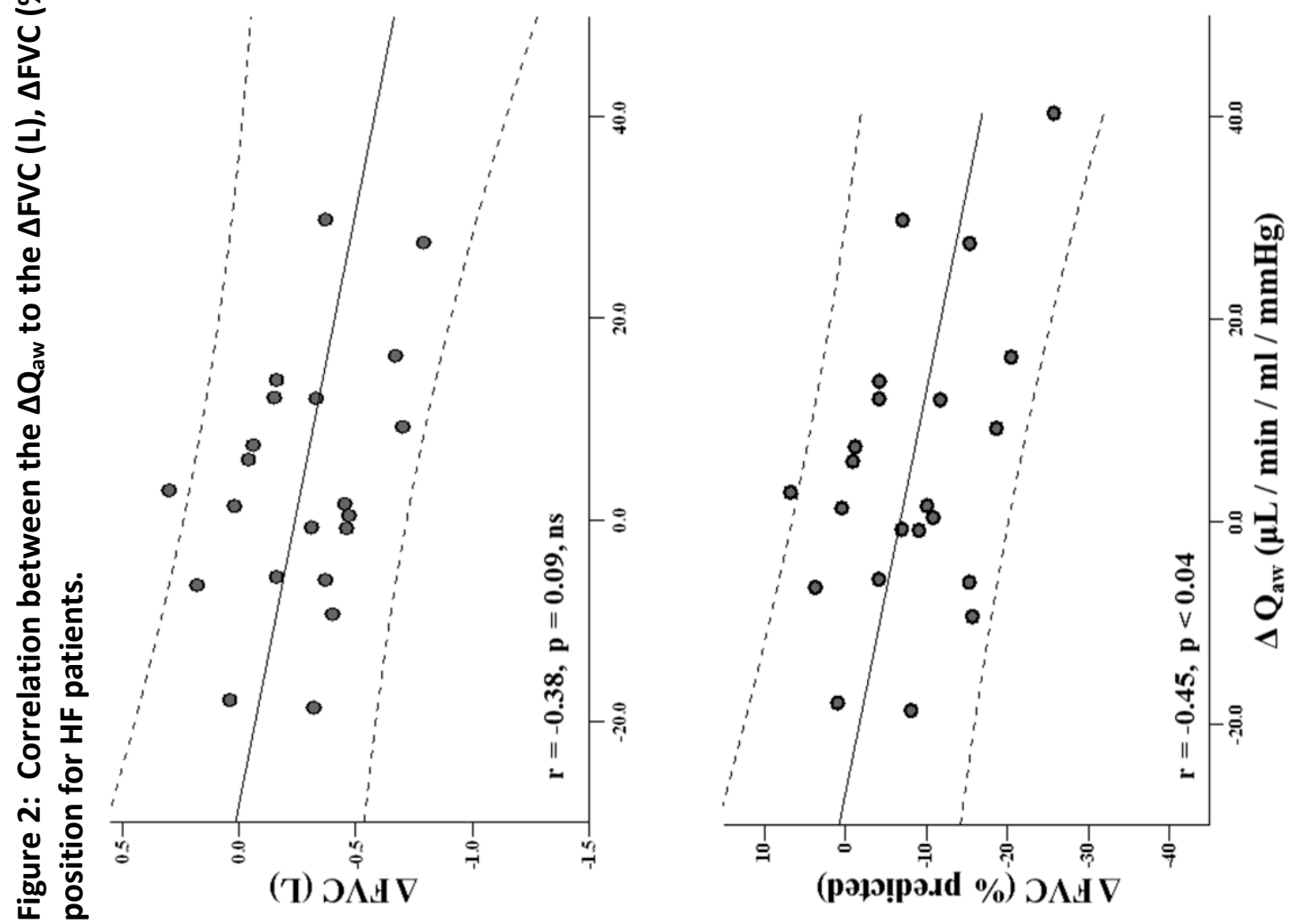
